\title{
A Systematic Literature Review of the IT-Based Supply Chain Management System: Towards a Sustainable Supply Chain Management Model
}

\author{
Chang-Tang Chiang ${ }^{1}\left(\mathbb{D}\right.$, Tun-Chih Kou ${ }^{2, *}$ and Tian-Lih Koo ${ }^{3}$ \\ 1 Department of Information Management, Chinese Culture University, Taipei 111, Taiwan; \\ arthurctchiang@gmail.com \\ 2 Department of International Business, Ming Chuan University, Taipei 111, Taiwan \\ 3 Department of Accounting, Shih-Chien University, Taipei 104, Taiwan; kootl@g2.usc.edu.tw \\ * Correspondence: fredonef@hotmail.com
}

Citation: Chiang, C.-T.; Kou, T.-C.; Koo, T.-L. A Systematic Literature Review of the IT-Based Supply Chain Management System: Towards a Sustainable Supply Chain Management Model. Sustainability 2021, 13, 2547. https://doi.org/ 10.3390/su13052547

Academic Editor: Andrea Appolloni

Received: 7 February 2021

Accepted: 22 February 2021

Published: 26 February 2021

Publisher's Note: MDPI stays neutral with regard to jurisdictional claims in published maps and institutional affiliations.

Copyright: (c) 2021 by the authors. Licensee MDPI, Basel, Switzerland. This article is an open access article distributed under the terms and conditions of the Creative Commons Attribution (CC BY) license (https:// creativecommons.org/licenses/by/ $4.0 /)$.

\begin{abstract}
The concept of sustainability has been highly valued by all aspects of life, while the supply chain plays a critical role in production and logistics. Supply chain management (SCM) is continuously transformed by information technology (IT). The purpose of this study is to review and discuss the effect of information technology-based SCM on sustainability. This paper conducted a systematic literature review by collecting author-anchored keywords from peer-reviewed articles on IT-based supply chain management. A total of 1264 articles and 2575 keywords from eleven supply chain-related journals were analysed with social network analysis. A knowledge map with ten research hot topics was identified. Additionally, a sustainable supply chain management (SSCM) model is developed not only to guide researchers to further understand IT-based SCM topical and structural meanings but also to contribute to enlightening a coherent and rigorous body of theories relevant to academics and supply chain and logistics managers interested in SSCM.
\end{abstract}

Keywords: information technology; sustainable supply chain management (SSCM); keyword analysis; IT innovation capability; supply chain integration; risk management; collaboration

\section{Introduction}

In increasingly volatile business environments, supply chain managers must determine how to deliver services/products to their customers in a context that involves multiple partners facing globalization pressure and environmental uncertainty. How to balance "the triple bottom line" (e.g., economic, environmental, and social values) has become one of the greatest challenges that a supply chain manager is facing [1-3]. To cope with these challenges, IT, with the capability to connect and integrate people, processes and devices among focal organizations, has long been recognized as an effective and efficient instrument to actualize organizational strategies [4].

However, few studies have comprehensively focused on the impact of IT in the sustainable SCM and logistics fields. In particular, there is a research void on the themes and synergies in these fields. Correspondingly, the present study aims to fill this void and answer the following research question: How is IT positioned with respect to other factors of relationships in the sustainable SCM and logistics domains? Specifically, this study plans to understand (1) what are the main IT applications in current SCM, (2) what are the key successful factors that influence IT-enabled SCM implementation, and (3) what is the role of IT in a sustainable supply chain?

To fill this gap, it is crucial to present a comprehensive and systematic literature review by quantifying the method and demonstrate the results in a visual classification scheme. To achieve IT-enabled SCM and comprehensive goals, this study also utilizes author-anchored keywords from high-impact SCM journals to analyse the hotspots of 
IT-based SCM research. With the support of data visualization and social network analysis (SNA) techniques, information overload can be limited by using visual representations. This article will not only aid SCM managers and academic researchers in better understanding the research synergies, gaps, and implications of IT-based sustainable supply chain management research but also contribute an innovative method, using keyword-based analysis and SNA, to quantitatively and visually discover a knowledge profile of supply chain (SC) and logistics research.

The manuscript is structured as follows. Section 2 outlines the background of the study, which contains keyword analysis, social networks, and SCM review subsections. Then, Section 3 presents the methods, and Section 4 demonstrates the findings of the review. The IT-enabled SCM research themes and implications are discussed in Section 5. Finally, Section 6 summarizes the main conclusions and future research.

\section{Background of the Study}

\subsection{Keyword Analysis}

Originating from information and library science, keyword analysis is a stream of bibliometric analysis defined as the study of the quantitative aspects of the production, dissemination and use of recorded information [5]. Scholars use bibliographic information such as authors, research institutions, author-anchored keywords, or references to quantify the scientific impact of a particular field. Keywords are terms or phrases that most appropriately describe the document topic, which authors are requested to add in the scientific article at the time of submission to a journal. Keywords are important because they reflect the subject matter of articles and represent authors' understandings of their work within the thematic context of their research domains [6]. Keywords represent the "central poles" of an article, and researchers might collect the keywords from multiple articles to perform more detailed explorations of research topics as well as emerging and fading themes over a period of time [7]. Thus, the application of keywords enables scholars to uncover research themes, interests, synergies, and methodologies with a focus on a particular subject area as well as to discover the area under research.

\subsection{Social Network Analysis}

SNA is a typical quantitative method that depicts individual actors (also termed "nodes") and the relationships (also termed "ties") between actors in a network structure [8]. SNA is widely applied in sociology to understand social structure. Wasserman and Faust [9], for example, conceptualize social structure as a network with social ties that connect actors and relevant resources. The authors utilize SNA to detect structural patterns, identify how these patterns form, observe how the social relationships interrelate, and analyse the implications of the behavioural patterns for network actors. Applying SNA to keyword analysis, a keyword represents a node in a social network, and the relationships (ties) occur when the author specifies the keyword list in a paper. A subnetwork is formed comprising the keyword list in an individual article, while a comprehensive knowledge map emerges by the aggregation of author-anchored keywords located in various articles in the same discipline. The advancement of IT and the increase in computing power in recent decades make it possible that a large number of author-anchored keywords can be analysed and information can be more easily interpreted by means of data visualization techniques. Both scholars and practitioners reap benefits from analytic insights, and visual presentation reduces large and messy data into condensed and concise information for communication.

\subsection{SCM Review}

Many SCM papers focus on IT, contributing substantially to SCM and its relevant hotspots. However, the overall body of research in this field remains fragmented, and reviews of the impact of IT on SCM are lacking or somewhat outdated. Ralston et al. [10], for example, their review article mainly focuses on supply chain collaboration, while another review work from Jain and his colleagues solely concerns e-fulfillment [11]. Given 
the radical and evolutionary nature of IT and SCM, providing a review of current new developments is salient to keep researchers, practitioners, and interested readers informed about the latest IT developments and practices in the contexts of SCM and logistics. A timely review of academic research in this field can generate theoretical and managerial implications regarding SCM and aid SCM development. A literature review is a systematic, transparent, and reproducible process to identify, evaluate and interpret current literature and help develop a reliable knowledge base by accumulating knowledge from a range of studies [12,13]. Ralston et al. [10] argued that it is necessary for academic scholars to regularly review prior literature in their fields because revisiting extant research on specific research domains can support researchers in examining what has already been investigated and what remains to be analysed in corresponding research areas. Indeed, research articles are an independent, vital, and unbiased crystallization of accumulated and state-of-the-art knowledge in a field of study. Supply chain practitioners can apply empirical outcomes or conceptual frameworks from scholarly research to their businesses to remain sustainable and competitive.

\section{Methods}

The major contribution of a literature review article is to "provide a historical perspective of the respective research area and an in-depth account of independent research endeavors" [14] (p. 233). Classical literature reviews (CLRs) are informative in discovering general and visible aspects of a particular research field; however, they fall short in revealing hidden structures and properties of research domains [15]. In addition, these reviews typically select target articles by performing a specific keyword search in a database and manually determining whether to seek pertinent papers from the references [16]. Based on this methodology, the research outcomes might be subject to reviewers' biases and articles' selection and interpretation.

A systematic literature review (SLR) overcomes the identified drawbacks of CLR, such as narrative reviews and a lack of thoroughness [3,11]. In the SCM research field, scholars have called for more systematic review processes and transparent procedures as well as for inheritable paradigms [17]. The present study adopts an SLR, which is guided by the following standards: transparency, inclusivity, an explanatory nature, and a heuristic nature [18-20]. Based on recent systematic review literature, this study adopts a five-stage procedure (namely, question formation; locating studies; study selection and evaluation; analysis and synthesis; and reporting and using the results) to perform the systematic review and a transparent, replicable, and reliable assessment of the literature [18-20]. Each stage is described as follows.

Stage 1-Question Formation: The main question in the first stage was to clearly define the review question to guide the review and avoid ambiguity. The question was as follows: How is IT positioned with respect to other factors of relationships in the SCM and logistics domains? To reflect the characteristics of IT-based SCM and logistics research, the review question was deconstructed into three categories: themes, synergies, and implications.

Stage 2-Locating Studies: The second stage was to locate candidate studies. Business/management and high-impact journal articles were the criteria to identify the data sources. To meet these criteria, data sources were collected using the Social Science Citation Index (SSCI), and chosen journals had to have been listed in the SSCI at least five times in the past ten years. Since the SSCI database contains thousands of journals covering all scientific fields, the search terms "supply", "supply chain" and "logistics" were input to search the target journals. A total of eleven journals were selected because they are leaders in terms of their quality and the peer-reviewed publications they index, abstract or to which they provide access. Additionally, the profile of these databases is trustworthy and adheres to the principles of stability, reproducibility, and accuracy, which constitute the foundation of any quality domain literature review. The eleven journals obtained from the inquiry results are listed in Table 1. 
Table 1. Journal Title and Keyword Distribution.

\begin{tabular}{|c|c|c|c|c|}
\hline Journal Title & Papers & Percent & Keywords & Percent \\
\hline Asia Pacific Journal of Marketing and Logistics & 70 & $6 \%$ & 334 & $5 \%$ \\
\hline International Journal of Logistics Management & 252 & $20 \%$ & 1383 & $21 \%$ \\
\hline International Journal of Logistics Research and Applications & 57 & $5 \%$ & 290 & $4 \%$ \\
\hline International Journal of Physical Distribution \& Logistics Management & 251 & $20 \%$ & 1287 & $20 \%$ \\
\hline International Journal of Shipping and Transport Logistics & 26 & $2 \%$ & 200 & $3 \%$ \\
\hline Journal of Business Logistics & 39 & $3 \%$ & 203 & $3 \%$ \\
\hline Journal of Purchasing and Supply Management & 66 & $5 \%$ & 288 & $4 \%$ \\
\hline Journal of Supply Chain Management & 15 & $1 \%$ & 89 & $1 \%$ \\
\hline Maritime Economics \& Logistics & 13 & $1 \%$ & 73 & $1 \%$ \\
\hline Supply Chain Management: An International Journal & 407 & $32 \%$ & 1966 & $30 \%$ \\
\hline \multirow[t]{2}{*}{ Transportation Research Part E: Logistics and Transportation Review } & 68 & $5 \%$ & 457 & $7 \%$ \\
\hline & 1264 & $100 \%$ & 6570 & $100 \%$ \\
\hline
\end{tabular}

Stage 3-Study Selection and Evaluation: After the target journals were identified, the authors first used "information system", "information technology", "digital", and "computer" to search the prospective articles on the journal websites. To obtain comprehensive results of the impact of IT on SCM, this study did not limit any time period. Papers published in the period from the first publication of the journal to January 2021 were analysed to ensure that the information presented was complete and current. Second, the metadata of candidate articles were downloaded as research information systems (RIS) files-which are text file formats that record journal article information such as title, authors, keywords, and published year, provided by the journal index system-for later analysis. Third, the authors carefully read through the title, abstract, and keywords of each article from the RIS file list to determine whether the articles were suitable for further analysis based primarily on their direct relevance to IT. If this information was still unable to be judged, the authors read the full article thoroughly, and the authors with either an IT background or SC research experience had internal discussions to reach a consensus and minimize personal bias during the selection stage. Fourth, articles irrelevant to IT or information systems (IS) were removed from the analysis list, and only full-length papers published in the selected journals were included in this list. Research notes, book reviews, and editor prefaces were all excluded, as the authors assumed that original/research articles represent the most advanced source of knowledge and make more significant contributions to knowledge development in the SCM field. Finally, this stage yielded 1264 articles in total, as summarized in Table 1.

Stage 4-Analysis and Synthesis: Before data analysis, the author-anchored keywords in target articles were consolidated to a Microsoft Excel file for data purification. Because keywords are anchored by authors and individual keywords with the same concept can be expressed differently, each keyword was standardized to ensure its consistency (singular/plural) and unification (synonyms) [21]. Therefore, it took considerable time and effort to edit the keywords during the iterative process. For example, agencies were standardized to agency; information and communication technologies (ICTs), ICT, ICTs, and information and communication technologies were all standardized to information and communication technology; supply chain management, SCM, and supply chain management were all standardized to supply chain management; and organization was standardized to organization. Although some concepts might appear equivalent (e.g., outsourcing and purchasing; integration and SC integration) in the SC and logistics fields, this study regards them as different to retain the original meaning because the keywords were provided by the authors in the particular research context and because this study aims to avoid unnecessary debates [7].

After data cleaning, Gephi ${ }^{\mathrm{TM}}$, an open-source SNA software, was employed to map the keyword networks and explore research patterns. With the capability to support data visualization and deal with large data in complex networks, Gephi ${ }^{\mathrm{TM}}$ has been widely 
used in SNA across different disciplines, such as biology, genetics, management, and organization studies [22].

Stage 5-Reporting and Using the Results: Similar to empirical research in reporting results, the SLR formally reports the outcomes of the review process. This report should contain the abstract, introduction, methods, findings, discussion, and conclusion sections. The introduction addresses the research questions. The methods section reveals how the review was performed, namely, information sources, search criteria, study selection, data collection, and synthesis criteria. The findings and discussion sections provide at least a summary of the studies and a synthesis of the results. The conclusion section describes the practical and theoretical implications and limitations of the research as well as directions and agenda for future inquiries [18].

\section{Findings}

\subsection{Network-Level Properties}

According to the search criteria and the target journals, 1264 articles were identified from eleven journals, which contained 2575 unique keywords (nodes) and 12,611 connections (edges). The distribution of the 1264 articles by year is summarized in Table 2, and the published trend is displayed in Figure 1. The average degree was 9.795, and the average weighted degree was 10.811 . The network diagram was 7 , the graph density was 0.004 , the modularity was 0.482 , and the average clustering coefficient was 0.84 . The average clustering coefficient was high (0.81), whereas the network density was quite low (0.004). This outcome implies that research hotspots based on a set of closely related concepts (e.g., keywords) are used for academic reasoning, theorizing, and communication [21], and the scope of the research domain is widespread.

Table 2. Distribution of Publications by Year.

\begin{tabular}{cccccccc}
\hline Year & Number & Year & Number & Year & Number & Year & Number \\
\hline 1989 & 8 & 1998 & 13 & 2007 & 60 & 2016 & 79 \\
1990 & 9 & 1999 & 18 & 2008 & 72 & 2017 & 62 \\
1991 & 9 & 2000 & 33 & 2009 & 58 & 2018 & 105 \\
1992 & 14 & 2001 & 18 & 2010 & 60 & 2019 & 79 \\
1993 & 10 & 2002 & 29 & 2011 & 50 & 2020 & 92 \\
1994 & 9 & 2003 & 45 & 2012 & 49 & 2021 & 5 \\
1995 & 8 & 2004 & 40 & 2013 & 44 & & \\
1996 & 14 & 2005 & 56 & 2014 & 52 & & \\
1997 & 18 & 2006 & 66 & 2015 & 63 & & \\
\hline
\end{tabular}

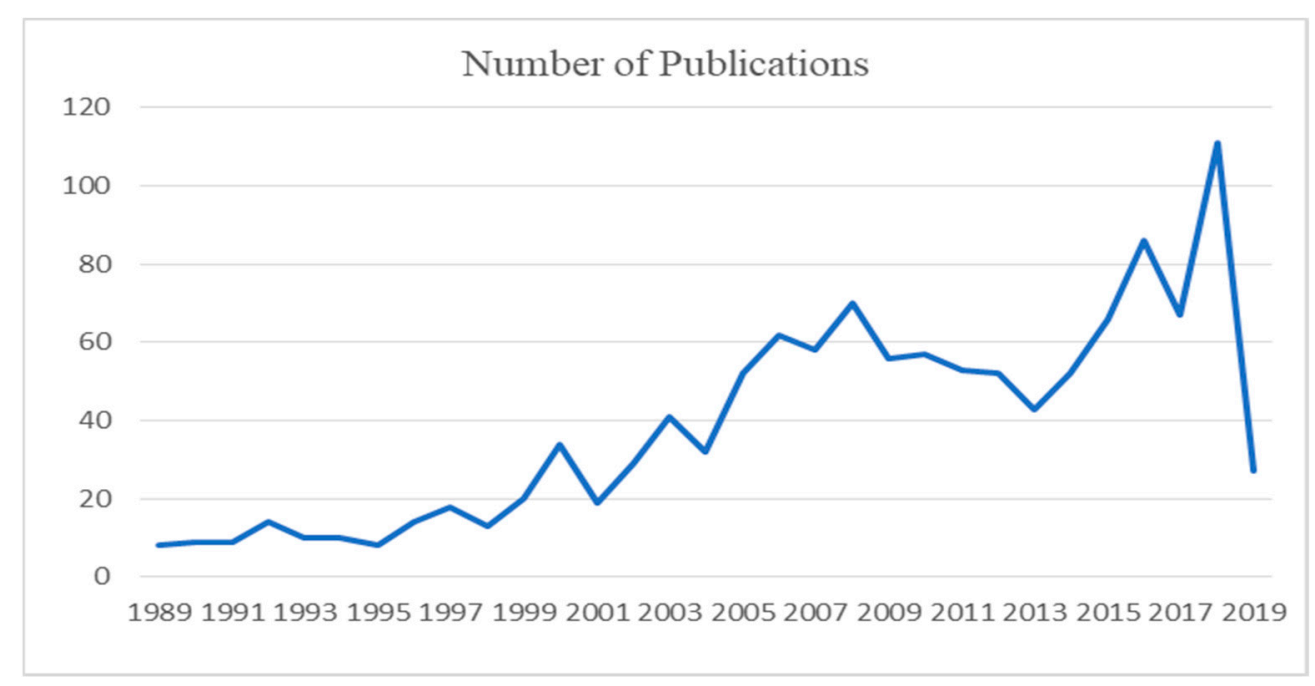

Figure 1. Diagram of Publication Distribution by Year. 


\subsection{Analysis of Keywords}

Unlike CLR, which mainly focuses on the measure of frequency in publications, quantitative keyword analysis is rooted in the perspective of centrality in the social network. The characteristics of the top 39 keywords in terms of frequency, degree, and weighted degree (greater than or equal to 78) are demonstrated in Table 3, and the comprehensive keyword network diagram is depicted in Figure 2.

Table 3. Top 39 Keywords and Their Properties.

\begin{tabular}{|c|c|c|c|c|}
\hline Oder & Keyword & Weighted Degree & Degree & Frequency \\
\hline 1 & supply chain management & 476 & 823 & 1439 \\
\hline 2 & logistics & 126 & 319 & 467 \\
\hline 3 & supply chain & 72 & 225 & 285 \\
\hline 4 & information technology & 66 & 200 & 269 \\
\hline 5 & distribution management & 72 & 172 & 223 \\
\hline 6 & case study & 50 & 189 & 216 \\
\hline 7 & electronic commerce & 56 & 163 & 201 \\
\hline 8 & information system & 47 & 147 & 184 \\
\hline 9 & China & 42 & 141 & 168 \\
\hline 10 & integration & 45 & 125 & 163 \\
\hline 11 & structural equation model & 35 & 139 & 156 \\
\hline 12 & Europe & 29 & 107 & 153 \\
\hline 13 & supply chain integration & 37 & 121 & 149 \\
\hline 14 & collaboration & 33 & 124 & 148 \\
\hline 15 & risk management & 35 & 92 & 131 \\
\hline 16 & purchasing & 32 & 100 & 118 \\
\hline 17 & sustainability & 21 & 95 & 108 \\
\hline 18 & Australia & 27 & 88 & 106 \\
\hline 19 & distribution & 25 & 86 & 105 \\
\hline 20 & big data & 18 & 89 & 101 \\
\hline 21 & innovation & 27 & 87 & 98 \\
\hline 22 & small to medium sized enterprise & 27 & 77 & 97 \\
\hline 23 & literature review & 21 & 85 & 97 \\
\hline 24 & outsourcing & 32 & 72 & 95 \\
\hline 25 & performance measurement & 26 & 75 & 95 \\
\hline 26 & reverse logistics & 25 & 84 & 92 \\
\hline 27 & modeling & 19 & 73 & 90 \\
\hline 28 & decision making & 20 & 75 & 90 \\
\hline 29 & food industry & 22 & 69 & 89 \\
\hline 30 & retailing & 25 & 71 & 89 \\
\hline 31 & performance & 21 & 79 & 89 \\
\hline 32 & systematic literature review & 24 & 70 & 88 \\
\hline 33 & resource based view & 16 & 77 & 84 \\
\hline 34 & radio frequency identification & 27 & 68 & 83 \\
\hline 35 & survey & 18 & 70 & 81 \\
\hline 36 & internet & 24 & 63 & 80 \\
\hline 37 & North America & 14 & 61 & 80 \\
\hline 38 & Asia & 14 & 71 & 79 \\
\hline 39 & competitive advantage & 22 & 67 & 78 \\
\hline
\end{tabular}




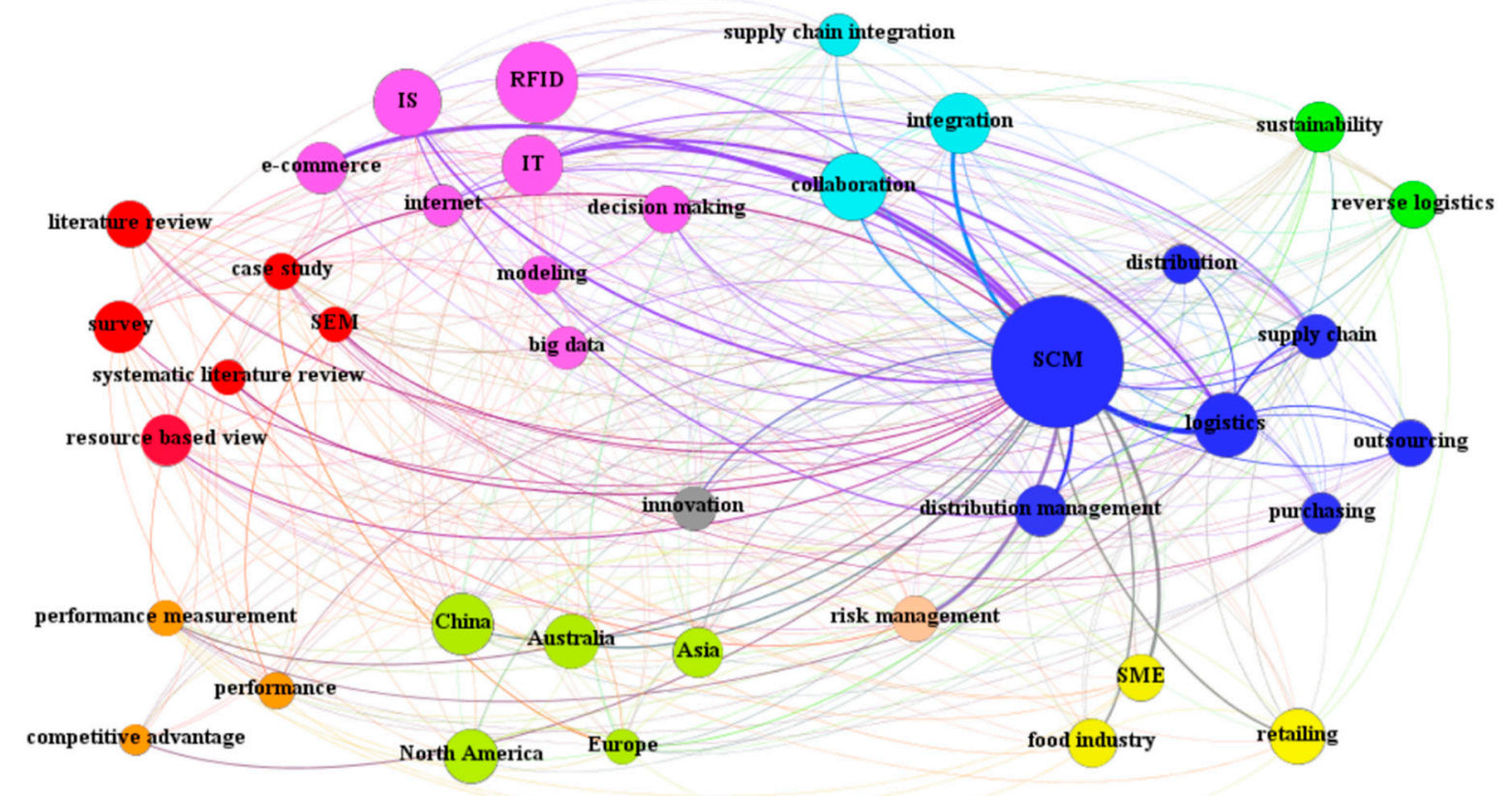

Figure 2. IT-based SCM keyword network diagram.

\section{Discussions and Implications}

\subsection{IT-Enabled SCM Research Themes}

Through the analysis of the top 39 IT-enabled SCM keywords displayed in Figure 2, ten main IT-enabled themes can be classified.

(1) SCM Crux: The SCM crux is the first theme and the essential concept of SCM; it involves the definition, main activities, and operation of SCM. The theme keywords include SCM, logistics, supply chain, distribution management, distribution, outsourcing and purchasing. SCM is defined as "the management of all activities within interdependent supply networks through the strategic development of relational capabilities, driven by extrinsic and intrinsic drivers, with the goal of continuously improving the performance of all members of the networks" [2](p.3). A characteristic of SCM according to this definition is that SCM is founded on labour collaboration in which network actors take responsibility based on specialization and create value to achieve network goals. A logistic firm in the SC, for instance, might leverage its purchasing or outsourcing policy to help managers significantly reduce costs and improve service performance [23]. Under the labour division principle, SCM partners focus on their roles to contribute added value to the SC and purchase or outsource other noncore business services/products from their suppliers.

(2) Firm Performance: Performance, performance measurement, and competitive advantage comprise the second theme. Firm performance, which is defined as the degree to which a supply chain firm's financial and other objectives are achieved through the execution of tactics, supply chain strategies, and management, reflects the effectiveness of strategic implementation that ultimately creates a sustainable competitive advantage. SCM researchers usually use operational or firm-level performance to measure a firm's performance. Inventory turnover, for instance, is a typical operational performance measure for empirical SC research, as it is more directly related to the SC process of interest than an indirect final performance measure such as return on investment (ROI) [24]. Firm-level performance, however, is often measured by financial and marketing performance. The extant literature shows that financial performance is defined as average profit, profit growth, ROI, and cash flow, while marketing-based performance can be measured as a multidimensional 
construct that includes annual sales growth, market share, product development, and market development $[25,26]$. Nevertheless, the review findings suggest that a stream of sustainable SC scholars have investigated firm sustainable performance in hierarchical order. They argue that SC performance should be measured not solely in the economic dimension (i.e., finance or marketing) but also by the influence of the SC on ecological and social dimensions [27]. To address this issue, these scholars propose a holistic performance evaluation model that includes the impact of the SC on economic, environmental and social performance measures [2,28].

(3) Supply Chain Capability: SC integration, integration, and collaboration are core constructs of SC capability. Integration is a key concept in SCM. Indeed, it is an essential prerequisite for SCM [29,30]. SC integration involves the alignment, linkage and coordination of information flow, organizational knowledge, employee capability, business processes, and strategies across the SC among all contact points and influences the acceleration of the efficient and effective flows of finance, products, information, and knowledge to meet customer requirements [31]. In providing synergy from seamless connectivity and simplification, SC integration enables partners to reduce redundancy, manage operational complexity, and enhance interfirm relationships. Supply chain collaboration, however, intends to foster superior performance in the SC because of the capitalization on resources, capabilities, processes, and routines residing in the partners [32]. As SC collaboration involves the sharing of information, people, and technology resources, SC members produce synergies for collective competitive advantages and against SC disruption [33]. Kilubi and Rogers propose that SC collaboration is capable of generating new knowledge by means of joint product research and design, technology sharing or collaborative process reengineering, which improves the capability of the SC to respond in a timely manner to environmental disturbances [34]. Although SC integration and collaboration differ in their definition and scope, SC scholars generally agree that both constructs are significantly linked to SC performance.

(4) Risk Management: Supply chain risk management (SCRM) aims at monitoring and controlling unanticipated events and implementing appropriate strategies through a coordinated approach among supply chain members to reduce supply chain vulnerabilities in a risky environment [34]. Zhu and his colleagues noted that the SC industry is subject to five risk sources: organizational risks (e.g., machine/delivery failure or staff turnover), market risks (e.g., demand uncertainty), supply risks (e.g., production/distribution uncertainty), technological risks (e.g., information leakage), and environmental risks (e.g., overall business context uncertainty). These scholars suggested that SC firms adopt information integration (e.g., the coordination of information transfer, collaborative communication and supporting technology), operational integration (e.g., joint development), and relational integration (e.g., long-term and closed relationships) to reduce the risk and uncertainties [35].

(5) IT as Resources: Among the keyword groups including decision making, modelling, Internet, radio-frequency identification (RFID), big data, IT, IS, and e-commerce, all are IT resources available for a firm to create a competitive advantage. These resources can be further conceptualized into three subcategories: decision support, IT, and IS. In the decision support subcategory, many relevant SC studies have examined how to effectively and efficiently manage distribution by leveraging the capability of IT to satisfy customer logistic requirements. Wang et al. [36], for example, developed a mathematical decision support model that assists a manager in scheduling, routing, and managing distribution. The difference between IT and IS in this study lies in the fact that IT refers to the hardware, software, methods, techniques, or algorithms that usually cannot operate independently, while IS refers to a system that contains IT components and is able to operate independently and interact with people or other systems. That is, IS encompasses IT, procedures, and people. Under this definition, IT, RFID, the Internet, and big data fall into the IT subcategory, while 
IS and e-commerce belong to the IS subcategory. Traditionally, the role of IS in an organization is to create value to improve organizational efficiency and effectiveness. An interorganization information system (IOIS) boosts intra- and interorganizational operational efficiency, direct logistics movement, and timely information sharing with SC parties [27]. Decision support enables firms to synchronize supply and demand by accurate inventory replenishment and order implementation as well as to optimize procurement, production, distribution, retailing and even post-sales services within complex and uncertain business processes [37]. An e-commerce system not only empowers the SC to create revenues but also achieves cost reductions for an organization and ensures the attainability of products/services at a lower price [38]. Therefore, an e-commerce system supports the development and realization of corporate strategy. Open standard technical protocols make it possible for Internet applications to offer real-time and globalized platforms for firms to share information with a wide range of channel partners (anytime, anyone, anyplace) at a lower cost and to provide firms with the ultimate benefits of reducing operations costs, improving service quality, enhancing customer satisfaction, and retaining competitive advantages [39]. With the emergence of RFID technology and big data analytics, data can be digitally collected from sensors and utilized to communicate with a firm and its SC partners, including suppliers, manufacturers, logistics, resellers, retailers and even customers, leading to a high degree of data transparency and fostering information exchange, agility and visibility. SC managers benefit from improved service quality at affordable costs, higher customer satisfaction, and decreased waste products from the insights of these big data analytics [40].

(6) IT innovation capability: Innovation involves the capacity to introduce new processes, products, or ideas in an organization to achieve efficiency [26]. Innovation creates SC value for customers and improves the quality of processes and products, particularly by means of innovative applications of IT [41]. The essence of new technology resides in exploring new alternatives whose returns may be uncertain, distant, or negative, whereas system implementation involves the exploitation, refinement and extension of current competencies, technologies, and paradigms, whose returns may be positive, proximate, or predictable [42,43]. Corresponding to the notions of IT and IS mentioned in the previous section, an organization explores the applicability of new technologies to learn about the environment and discover new approaches to creating value (e.g., scanning the market, collaborating with suppliers and customers, or improving SC or organizational performance) due to the immaturity and risk of new technologies. An organization, however, exploits IS to improve operational efficiencies (e.g., logistics scheduling or demand prediction) because IS is usually implemented by controllable and mature technologies to reduce risk. Consequently, these analyses indicate that IT innovation capability is a reflective construct that contains two constructs: technology exploration capabilities and system exploitation capabilities.

(7) Stakeholder Engagement: Sustainability and reverse logistics comprised the seventh theme identified from the keyword map. Sustainability, which refers to meeting the needs of present generations without compromising the ability of future generations to meet their needs [44], is a comprehensive and virtuous scorecard to measure SC performance. Firms shift their focus towards sustainability objectives to reduce their impact on the environment and their growing demand for materials. Moreover, reusing products can contribute to sustainability due to the recycling of residual value. Reverse logistics, also called a closed-loop supply chain (CLSC), involves making full use of the residual value of consumed products, and it is a way to exercise sustainability. For instance, Paula et al. [33] posited that reverse logistics should not be limited to the time that waste is generated and sent for recycling or environmentally friendly disposal; rather, reverse logistics should be considered throughout the product lifecycle, minimalizing the environmental impact of product design, packaging, storage, delivery, and recycling. Rooted in a customer-centric perspective, the SC 
strategy of asking not "What is the right supply chain for companies?" but "What is the right supply chain for customers?" can be assessed by a deeper and more insightful performance evaluation and gives SCs responsibility for the environment and society [45].

(8) Supply Chain Context: The eighth theme relates to the research context and includes the keywords food industry, retailing, and small and medium-sized enterprises (SMEs). SC scholars pay considerable attention to the food industry because food has the characteristics of perishability and ease of suffering caused by microbial spoilage, and it has a substantial impact on people's well-being and distribution, especially in food-inflated countries [46]. Retailing is another topic that draws SC researchers' interest given the success of e-commerce and online shopping. However, new challenges arise when customers require fast service and multiple channels must be managed synergistically to provide a satisfactory shopping experience [47]. Ominchannel was initialized to satisfy such customers' expectations. IT capabilities make it feasible for an e-commerce retailer to redesign the distribution network, dynamically plan the inventory capacity, and assort different channels to provide a seamless and consistent consumer experience [48]. Logistics and SC networks are collaborative value ecosystems in which all actors (i.e., manufacturers, logistics suppliers, and customers) create, deliver, or add value to each other [49,50]. The role of SMEs in the network demonstrates that the value that an actor can contribute is more important than the business size of an actor in the network. SMEs in SC and logistics research also reflect the diversity of research in this field, as scholars do not solely focus on industrial giants.

(9) Research Location: Another diversified indicator is research locations, which include North America, Europe, Australia, Asia, and China. Areas such as Africa or South America do not stand out in the keyword map; however, there are articles that address these regions [46,51]. The geographic diversity in Figure 2 shows that an SC firm configures its organizational structure and optimizes resource allocation to build an integrative and harmonious supply chain network to reduce overstocking, increase time savings, and increase delivery in a specialized and competitive environment [52].

(10) Research Foundation: Structural equation modelling (SEM), surveys, literature reviews, SLRs, resource-based views (RBVs), and case studies are the research foundations of SC research. RBV provides the rationale that underpins IT as a strategy enabler. By implementing IT in its SC process, a firm is able to develop higher SC capabilities, which transform into firm-specific resources and create superior value that other competitors have difficulty duplicating [26,53]. IOIS deployment is regarded as resource acquisition, and a firm captures the benefits of intraorganizational integration, SC and logistics integration, logistics competencies, and organizational performance $[25,54]$. However, an IOIS encompasses multiple organizations with different interests, business processes, cultures, values, and strategic objectives, and this complexity makes its deployment subject to failure [55]. Analyses imply that successful IOIS implementation involves not only allocating sufficient resources to build up the IOIS but also aligning the compatibility among participating organizations. Furthermore, to survive in a radically changing environment, a firm and cross-SC partners should facilitate flexibility and adaptability among organizations via integrative IOIS. That is, to create irreproducible supply chain capabilities to deal with uncertain environments and duplication by competitors, it is crucial that an SC firm leverage interaction-enabling technologies to develop a dynamic capability to exchange information and coordinate and integrate cross-functional and boundary-spanning activities.

Surveys, literature reviews, and case studies are the main methods in SCM research. Surveys were found to be the most preferred empirical research design among researchers, and the use of questionnaires is the most prominent method of quantitative data collection [48]. Usually, accompanying the survey method, SEM is one of the most popular 
methods to investigate theoretically causal relationships due to its sophisticated data analysis techniques, while advanced statistical techniques need to aim for higher sample sizes [56]. An interesting finding is that both literature reviews and case studies stand out from the keyword network. In addition to providing rich data and an in-depth understanding of complex and multifaceted SC relationships, case-driven research approaches are well suited to exploratory study, especially when the phenomenon under development or the context under investigation is not easily separated [57]. A literature review, however, is capable of identifying knowledge gaps to be bridged to enrich the existing body of knowledge further [17]. Thus, such a review is necessary for providing an agenda for future research in the growing but underresearched field, which potentially has high managerial implications [37]. The coexistence of case studies and literature reviews suggests that IT-enabled SC research is long standing but still evolving and transforming. The relationships among these ten themes are depicted in Figure 3.

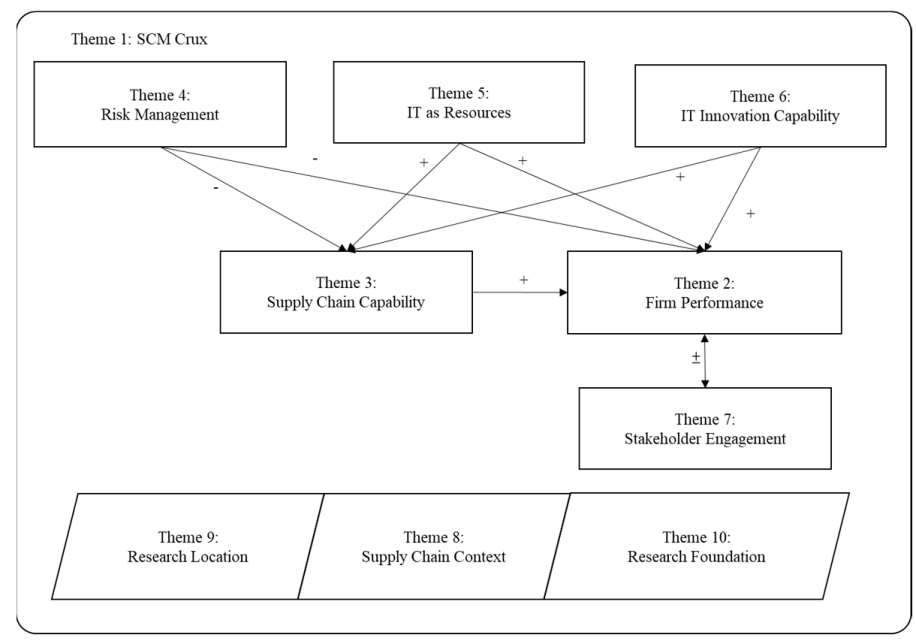

Figure 3. The relationships among ten themes.

\subsection{Implications}

The findings indicate that IT-enabled SCs are regarded as valuable, unsubstitutable, rare, and imitable resources to create and maintain sustainable advantages in an SC ecosystem $[26,53]$. Implemented IS and acquired IT skills are outcomes in which an organization allocates and configures IT resources. However, resource investment is a necessary condition. An organization also relies on IT professionals and domain experts to put these resources into effect. Effectively integrative and collaborative IOISs require sophisticated technologies and capable IT specialists to employ these resources to achieve sustainable advantages. Conceptualized service-dominant (S-D) logic views operand resources usually as tangible and static resources and skills, competencies, capabilities and knowledge as operant resources of competitive advantage [49]. To achieve SC integration and collaboration, SC partners should develop dynamic capabilities to integrate, build, and reconfigure internal and external resources and competencies to confront externally changing environments [58,59]. IT innovation capabilities, which are defined as a supply chain partner acquiring new technology or deploying system deployment to reach the effectiveness of the supply chain, serve as capabilities to obtain and learn innovative forms of collective activities and new resource configurations through which an SC firm can generate and modify operating processes to achieve strategic deliberation.

Incremental and radical innovation is inherent to IT, and new technologies always emerge to transform the business model of an SC. Focal firms should develop IT innovation capabilities, a second-order construct that can be further disaggregated into two capacitiessystem exploitation capability (SEC) and technology exploration capability (TEC) - to capture IT innovation capabilities in a turbulent era [60]. SEC in this study refers to a firm leveraging proven or highly developed IT to implement IOIS to create advantages, while 
TEC involves a firm exploring the eligibility of new technology in a particular facet of an SC. The dichotomized difference between SEC and TEC resides in reducing risk and uncertainty. As it involves engaging in variation, risk taking, and experiments with high instability in the reliability of performance, TEC is favourable for the implementation of proof-ofconcept projects by developing new knowledge pursuit of new business opportunities [42] Conversely, SEC emphasizes diffusion, refinement, and reuse of existing knowledge to create definable benefits such as cost reduction, process consistency, and process quality [42]. E-commerce serves as an example. Because e-commerce has been highly developed and internet technologies have been well proven, a firm might mainly focus on business processes and operation efficiency [11]. On the other hand, an online retailer might explore the applicability of big data to customers' online behaviours and preferences to implement personalized services or recommendation mechanisms.

Within boundary-spanning networks, business partners with high SC integration tend to be highly embedded operationally, technically, and strategically through resource complementarity and specialization. Integrated SCs provide operational transparency and a smooth-running and labour-saving flow of goods that diminish the time interval between a customer's order for a service and its delivery [61]. Business partners need to develop both SEC and TEC capabilities to achieve higher integration. In an SC, SEC empowers partners to create, transform and share information across organizational boundaries and makes the entire chain more closely connected. Additionally, TEC enables partners to use novelty technologies to differentiate their SC from other SCs by exploring new business opportunities, and it enhances SC performance. Thus, the first proposition is developed.

P1: A firm's IT innovation capability has a positive impact on its SC integration.

Collaboration is defined as partners working together and investing joint effort towards achieving a mutual goal, with a better chance of success than partners could have by acting alone. Cross-organization IT collaboration can be broadly defined as any joint inputs from independent firms towards a common goal that involves the use of ISs [32]. Higher degrees of collaboration, which also reflect higher levels of integration, focus on the long-term benefits of relationships, ultimately increasing firms' competitiveness and reducing transaction costs [33]. Collaboration makes the implicit areas of the relationships explicit and manageable on the basis of trust and information transparency. Prior research has demonstrated the critical role of IT capability in developing and maintaining successful interorganizational collaborations [62]. IT capability is an important factor in SC collaboration because it fosters an information sharing and collaboration communications system that enables SC information to be more transparent and visible [62]. Seamless information flow in relation to demand forecasting, product specifications, production planning, stock level, and delivery status are typical information shared with SC partners for effective SC performance in collaboration. Simultaneously, IT serves as an agent to exchange this information, and the new digital value chain reconfigures and expands the classical value chain created by tangible resource-based linkages, ensuring better coordination of collaborative planning, forecasting and replenishment (CPFR) [63]. To share and interflow, SC partners require explorative and exploitative IT capabilities to seek new IT resources to create and capitalize on business opportunities and utilize existing IT resources to extend and improve their business operations. Therefore, the second proposition is developed.

P2: A firm's IT innovation capability has a positive impact on its collaboration with SC partners.

Although the relationships described above appear to be conclusive, scholars have found that the dependencies inherent to integration and the complexity of information flows lead to risks in SC connectedness [64]. Moreover, extensively utilizing IT systems to satisfy customers' requirements increases the vulnerability of an SC. Due to lack of ownership, cyber information risks such as worms, viruses or Trojans from one partner might instantly propagate to all other partners in the chain. These risks might be promoted from the organization level to the network level, and their magnitude and probability can significantly influence the performance of the entire chain. Accidents become unpreventable 
or even routinized in complex and tightly coupled environments [35]. The involved firms suffer from losing integrative business benefits and maintaining competitive advantages. The ability of risk management might also influence the process of capability fulfilment. A firm with higher IT innovation capability might hedge these risks during IOIS design or mitigate the negative impacts of these risks to reduce damage when an incident occurs. Thus, the proactive or reactive ability to handle the occurrence of unexpected events and to alleviate their negative consequences in different circumstances is a determining factor of the entire SC performance [26]. Drawing on these arguments, the following proposition is proposed.

P3a: The capability of risk management moderates the effects of IT innovation capability on SC integration.

In addition to organizational and network risk, environmental uncertainty is the third source of SC risk. Environmental risks resulting from sociopolitical activities, accidents, or disruptive events affect business processes, operational control, supply, and demand risk at both the organizational and network levels. Firms are becoming more reliant on IT to manage information for decision making and collaborate with SC partners in uncertain environments. In other words, information processing capability enables a firm to cope with environmental risk and manage uncertainty related to planning, innovation, operational, and logistics activities [62,65]. Data quality is a critical indicator to measure a firm's information processing capability because exchanging real-time and accurate data with partners is regarded as the foundation of reducing uncertainty and improving the decisionmaking process [62]. Accordingly, a firm with a high IT innovation capability is capable of leveraging its TEC to explore fresh insights from big data analytics and to leverage its STC to generate reliable information from current systems for SC collaboration [66]. Therefore, the following proposition is proposed.

P3b: The capability of risk management moderates the effects of IT innovation capability on collaboration.

The outstanding keywords clearly reveal that sustainability has drawn scholars' attention in a time where there are global warnings about environmental issues. Sustainable development is becoming a critical challenge for firms to face increasingly worse environments. However, a firm might fall into a predicament when dealing with the challenges of environmental issues alone. Integration is an issue that not only affects procurement departments but also extends to legal, research and development (R\&D) production and marketing departments. It involves strategic integration and product/process development integration from the perspective of internal integration [54]. Moreover, information and resources located in SC partners need to be integrated to achieve environmental performance [67]. Schaltegger et al. [28] argued that compared with traditional SCs, sustainable SCs have more prominent characteristics of enhanced communication, technological integration and partner selection. Effective green integration makes it possible for the barriers of functional silos to be decomposed and for the operation process of the entire chain to improve, resulting from information integration and the sharing of risks and interests among cohesive SC parties. Previous literature also demonstrates that integration is positively related to sustainability. For instance, Vachon and Klassen [68] found that close SC integration with customers was significantly associated with pollution control. Therefore, the fourth proposition is developed.

P4: SC integration positively affects a firm's sustainability.

The sustainability issues that a firm encounters go beyond environmental and economic responsibility; social sustainability, such as employees' well-being, health and safety in an SC, must also be addressed. Research widely agrees that sustainability cannot be achieved by a firm alone but must involve all parties in an SC in the whole product life cycle, from product design, production, and logistics to recycling $[28,69,70]$. Scholars contest that collaboration is a feasible course of action to balance the triple bottom line of sustainability [71]. Collaborating with suppliers and customers enables a firm to maximize the 
utility of resources and capabilities for sustainable development, which leads to superior competitiveness; thus, collaboration is highlighted as a solution to achieving sustainability performance [28]. A recent review article from Brömer et al. [1], for example, suggests joint product development and design with suppliers and customers as a means to achieve sustainable performance. Meanwhile, effective sustainability performance largely relies on knowledge sharing between SC partners [54]. This article implies that SC collaboration involves sustainable management, requiring the allocation of specific resources for joint activities and knowledge sharing to attain sustainability objectives [32,70,72]. Green or eco-friendly products, knowledge about specifications, and process requirements contain rich information for partners to communicate and exchange. Information asymmetry barriers must be removed throughout the chain from suppliers to customers. Successful sustainability cannot be manifested without collaboration within and real commitment to an SC system. Therefore, the fifth proposition is developed.

\section{P5: Collaboration positively affects a firm's sustainability.}

A prior study suggests that customers with higher environmental involvement have a higher tendency to purchase green products [73]. Sustainability initiatives can be more easily implemented in an SC that considers the employment of advanced integration and collaboration as mechanisms that can increase SC density as well as a collection of interconnected organizations competing against other SCs, as opposed to independent organizations [28]. Sustainability practices can not only solidify an organization's legitimacy and social approval but also enhance the organization's prestige and brand reputation, which is a substantial asset in the SC, and further enhance the marketability of offerings [2] Thus, developing an indeed sustainable SC can be viewed as a valuable resource that is able to create a long-term and sustained advantage as well as enhance firm performance [74]. Hence, the sixth proposition is postulated, and the relationships among these six propositions are displayed in Figure 4:

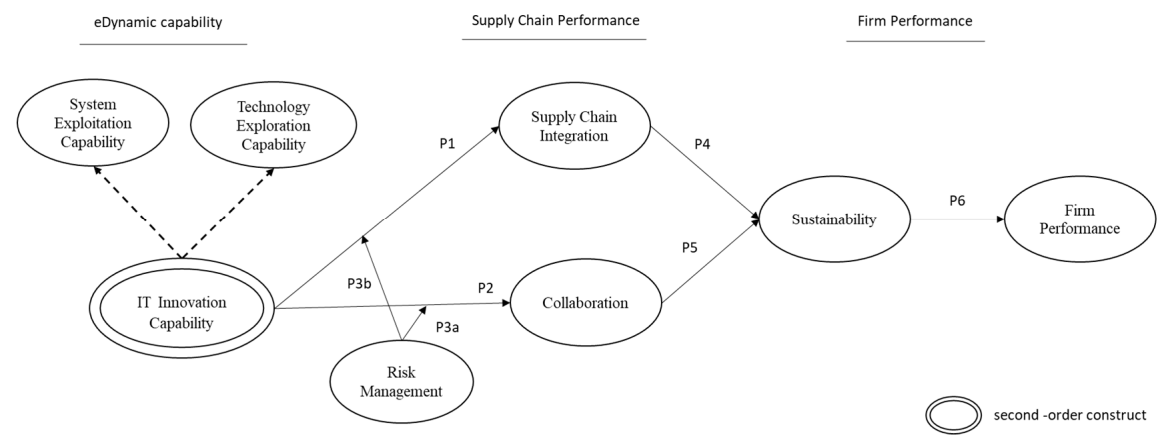

Figure 4. IT-based SSCM model.

P6: A firm's sustainability is positively related to its performance.

\section{Conclusions and Future Directions}

Author-anchored keywords in journal articles represent the distillation of academic knowledge. A group of keywords influence and reflect the evolution and diffusion of the body of domain knowledge in which a group of scholars passionately debate and dialog to maintain and enhance scientific rigor. To comprehensively understand the role of IT in SCM, this study reviewed 1264 journal articles and identified 2419 keywords. The results revealed ten research themes that describe the current state and evolution of IT in SCM. The results also have several academic and practical implications.

As a research article, this systematic review faces several limitations. First, the data sources were limited to eleven journals in the SC and logistics fields. Other IS, operation, social responsibility, sustainability, or environmental management field journals were excluded from the scope. Hence, caution must be used in generalizing the themes generated 
from this study to other IS, business, or sustainable management fields. Future elaboration might include more academic journals for better generalizability. Since SC and logistic research are well established and the dynamic nature of IT is increasingly transforming SCs and logistics fields, similar critical review studies are encouraged to be periodically duplicated or replicated to explore new phenomena and agenda relevant to academia and practitioners.

Second, IT continues to disrupt the business environment, and this study uses the general term IT/IS to cover all categories of IT; this broad scope is another limitation of this study. The state of emerging technology and its role in SCs and logistics in practice has likely exceeded what is reflected in the peer-reviewed literature. Future studies might focus on a particular IT field to narrow this gap by considering conference proceedings, workshops, technical papers, or business reports. Since IT innovation capability is a reflective construct that comprises TEC and SEC, it would be interesting to investigate the transitions or relationships between TEC and SEC for IOIS.

Another future research direction is to focus more on the role of IT in SSCM, which will extend the benefits to society as a whole. Likewise, developing SSCM maturity models is promising. SCM is complex and involves units, organization, SC, IT, processes, stakeholders, geo-locations, and products; thus, measuring the capability maturity of a supply chain not only reveals the soundness of an SC industry but also leads the industry to sustainable development. Further understanding the impact of IT on SCM is still relevant. More future research agenda are summarized in Table 4. We look forward to more research on developing new frameworks to better describe, explain, and predict the transforming role of IT in SCM.

Table 4. Future Agenda of IT-enabled SSCM.

Topic Technologies

Supply Chain Performance

Firm

Performance

\section{Future Agenda}

(1) Big data analytics for integrating production data, sensor data, and social media data for reducing demand uncertainty and envisioning the visibility of supply chains.

(2) Inter-organizational big data sharing and synthesis.

(3) The benefits or utilities of a mix of IT-facilitated realities (e.g., augmented reality, virtual reality, and mixed reality) on green product development, production, testing, logistics or recycling.

(4) Identifying defective products patterns by image recognition or computer vision.

(5) IT innovation capability scale development and validation.

(6) The leverage of emergent technologies (e.g., artificial intelligence (AI), big data analytics, smart factory, or RFID) on sustainability.

(1) Inter-organizational knowledge management.

(2) Inter-organizational agent integration and collaboration for order acquisition, logistics, scheduling, dispatching, and decision making.

(3) IT-enabled integration metrics development (e.g., IT density measures).

(4) Unsupervised and/or supervised learning algorithms to mine patterns related to SC risks or assist in risk identification.

(5) The role of emergent IT on collaboration and integration for green supply chain.

(6) Assessing the relationship among SC collaboration, integration, and risk management of vendor managed inventory (VMI) supply chain with emergent technologies.

(1) Learning-based classification and prediction for production waste estimation, assessment, reduction and cycling.

(2) Leveraging the capability of supportive technologies (e.g., chatbots or robotics) for customer service.

(3) Examining and investigating the tangible or intangible contributions of emergent applications (i.e., chatbots, robotics, blockchain, AI, augmented reality (AR), virtual reality (VR), mixed reality (MR), fifth generation (5G) or Internet of Things (IoTs)) on sustainability.

(4) Developing process models to construct supply chain sustainability.

(5) Validating the proposed model.

(6) Assessing the feasibility of governmental IT subsidy on reverse logistic.

(7) Smart factory performance and sustainability 
Author Contributions: Original draft, C.-T.C.; Conceptualization, T.-C.K.; Review \& editing, T.-L.K. All authors have read and agreed to the published version of the manuscript.

Funding: This research was partially funded by the Ministry of Science and Technology, Taiwan, R.O.C. under Project No. MOST 108-2410-H-034-005.

Institutional Review Board Statement: Not applicable.

Informed Consent Statement: Not applicable.

Data Availability Statement: Not applicable.

Conflicts of Interest: The authors declare no conflict of interest.

\section{References}

1. Brömer, J.; Brandenburg, M.; Gold, S. Transforming chemical supply chains toward sustainability-A practice-based view. J. Clean. Prod. 2019, 236, 117701. [CrossRef]

2. Chen, I.J.; Kitsis, A.M. A research framework of sustainable supply chain management: The role of relational capabilities in driving performance. Int. J. Logist. Manag. 2017, 28, 1454-1478. [CrossRef]

3. Correia, E.; Carvalho, H.; Azevedo, S.; Govindan, K. Maturity models in supply chain sustainability: A systematic literature review. Sustainability 2017, 9, 64. [CrossRef]

4. Kou, T.C.; Chiang, C.T.; Chiang, A.H. Effects of IT-based supply chains on new product development activities and the performance of computer and communication electronics manufacturers. J. Bus. Ind. Mark. 2018, 33, 869-882. [CrossRef]

5. Tague-Sutcliffe, J. An introduction to informetrics. Inf. Process. Manag. 1992, 28, 1-3. [CrossRef]

6. Uddin, S.; Khan, A. The impact of author-selected keywords on citation counts. J. Informetr. 2016, 10, 1166-1177. [CrossRef]

7. Su, H.N.; Lee, P.C. Mapping knowledge structure by keyword co-occurrence: A first look at journal papers in Technology Foresight. Scientometrics 2010, 85, 65-79. [CrossRef]

8. Otte, E.; Rousseau, R. Social network analysis: A powerful strategy, also for the information sciences. J. Inf. Sci. 2002, 28, 441-453. [CrossRef]

9. Wasserman, S.; Faust, K. Social Network Analysis: Methods and Applications; Cambridge University Press: Cambridge, UK, 1994; p. 8 .

10. Ralston, M.P.; Richey, R.G.; Grawe, S.J. The past and future of supply chain collaboration: A literature synthesis and call for research. Int. J. Logist. Manag. 2017, 28, 508-530. [CrossRef]

11. Jain, N.K.; Gajjar, H.; Shah, B.J.; Sadh, A. E-fulfillment dimensions and its influence on customers in e-tailing: A critical review. Asia Pac. J. Mark. Logist. 2017, 29, 347-369. [CrossRef]

12. Tian, M.; Deng, P.; Zhang, Y.; Salmador, M.P. How does culture influence innovation? A systematic literature review. Manag. Decis. 2018, 56, 1088-1107. [CrossRef]

13. Wu, L.; Yue, X.; Jin, A.; Yen, D.C. Smart supply chain management: A review and implications for future research. Int. J. Logist. Manag. 2016, 27, 395-417. [CrossRef]

14. Mentzer, T.J.; Kahn, K.B. A framework of logistics research. J. Bus. Logist. 1995, 16, 231.

15. Khan, G.F. Social media-based systems: An emerging area of information systems research and practice. Scientometrics 2013, 95, 159-180. [CrossRef]

16. Qian, J.; Law, R.; Wei, J. Knowledge mapping in travel website studies: A scientometric review. Scand. J. Hosp. Tour. 2019, 19, 192-209. [CrossRef]

17. Seuring, S.; Gold, S. Conducting content-analysis based literature reviews in supply chain management. Supply Chain Manag. Int. J. 2012, 17, 544-555.

18. Denyer, D.; Tranfield, D. Producing a Systematic Review. In The Sage Handbook of Organizational Research Methods; Buchanan, D.A., Bryman, A., Eds.; Sage Publications Ltd.: Thousand Oaks, CA, USA, 2009; pp. 671-689.

19. Ruhlandt, R.W.S. The governance of smart cities: A systematic literature review. Cities 2018, 81, 1-23. [CrossRef]

20. Vitolla, F.; Raimo, N.; Rubino, M. Appreciations, criticisms, determinants, and effects of integrated reporting: A systematic literature review. Corp. Soc. Responsib. Environ. Manag. 2019, 26, 518-528. [CrossRef]

21. Choi, J.; Yi, S.; Lee, K.C. Analysis of keyword networks in MIS research and implications for predicting knowledge evolution. Inf. Manag. 2011, 48, 371-381. [CrossRef]

22. Calma, A.; Davies, M. Academy of management journal, 1958-2014: A citation analysis. Scientometrics 2016, 108, 959-975. [CrossRef]

23. Baldus, B.J.; Hatton, L. US chief procurement officers' perspectives on public procurement. J. Purch. Supply Manag. 2020, 26, 100538. [CrossRef]

24. Porterfield, T.E.; Bailey, J.P.; Evers, P.T. B2B eCommerce: An empirical investigation of information exchange and firm performance. Int. J. Phys. Distrib. Logist. Manag. 2010, 40, 435-455. [CrossRef]

25. Gupta, S.; Kumar, S.; Singh, S.K.; Foropon, C.; Chandra, C. Role of cloud ERP on the performance of an organization: Contingent resource-based view perspective. Int. J. Logist. Manag. 2018, 29, 659-675. [CrossRef] 
26. Yeniyurt, S.; Wu, F.; Kim, D.; Cavusgil, S.T. Information technology resources, innovativeness, and supply chain capabilities as drivers of business performance: A retrospective and future research directions. Ind. Mark. Manag. 2019, 79, 46-52. [CrossRef]

27. Shee, H.; Miah, S.J.; Fairfield, L.; Pujawan, N. The impact of cloud-enabled process integration on supply chain performance and firm sustainability: The moderating role of top management. Supply Chain Manag. Int. J. 2018, 23, 500-517. [CrossRef]

28. Schaltegger, S.; Burritt, R.; Varsei, M.; Soosay, C.; Fahimnia, B.; Sarkis, J. Framing sustainability performance of supply chains with multidimensional indicators. Supply Chain Manag. Int. J. 2014, 19, 242-257. [CrossRef]

29. Iskanius, P.; Kilpala, H. One step closer towards e-business-the implementation of a supporting ICT system. Int. J. Logist. 2006, 9, 283-293. [CrossRef]

30. Song, G.; Song, S. Fostering supply chain integration in omni-channel retailing through human resource factors: Empirical study in China's market. Int. J. Logist. Res. Appl. 2020, 24, 1-22. [CrossRef]

31. Stevens, G.C.; Johnson, M. Integrating the supply chain ... 25 years on. Int. J. Phys. Distrib. Logist. Manag. 2016, 46, 19-42. [CrossRef]

32. Soosay, C.A.; Hyland, P. A decade of supply chain collaboration and directions for future research. Supply Chain Manag. Int. J. 2015, 20, 613-630. [CrossRef]

33. Paula, I.C.D.; Campos, E.A.R.D.; Pagani, R.N.; Guarnieri, P.; Kaviani, M.A. Are collaboration and trust sources for innovation in the reverse logistics? Insights from a systematic literature review. Supply Chain Manag. Int. J. 2019, 25, 176-222. [CrossRef]

34. Kilubi, I.; Rogers, H. Bridging the gap between supply chain risk management and strategic technology partnering capabilities: Insights from social capital theory. Supply Chain Manag. Int. J. 2018, 23, 278-292. [CrossRef]

35. Zhu, Q.; Krikke, H.; Caniëls, M.C. Integrated supply chain risk management: A systematic review. Int. J. Logist. Manag. 2017, 28, 1123-1141. [CrossRef]

36. Wang, S.; Liu, F.; Lian, L.; Hong, Y.; Chen, H. Integrated post-disaster medical assistance team scheduling and relief supply distribution. Int. J. Logist. Manag. 2018, 29, 1279-1305. [CrossRef]

37. Chaudhuri, A.; Dukovska-Popovska, I.; Subramanian, N.; Chan, H.K.; Bai, R. Decision-making in cold chain logistics using data analytics: A literature review. Int. J. Logist. Manag. 2018, 29, 839-861. [CrossRef]

38. Wang, C.; Mao, Z.; Johansen, J.; Luxhøj, J.T.; O’kane, J.; Wang, J.; Chen, X. Critical success criteria for B2B E-commerce systems in Chinese medical supply chain. Int. J. Logist. Res. Appl. 2016, 19, 105-124. [CrossRef]

39. Liu, H.; Huang, Q.; Wei, S.; Huang, L. The impacts of IT capability on internet-enabled supply and demand process integration, and firm performance in manufacturing and services. Int. J. Logist. Manag. 2015, 26, 172-194. [CrossRef]

40. Birkel, H.S.; Hartmann, E. Impact of IoT challenges and risks for SCM. Supply Chain Manag. Int. J. 2019, 24, 39-61. [CrossRef]

41. Michalski, M.; Montes, J.L.; Narasimhan, R. Relational asymmetry, trust, and innovation in supply chain management: A non-linear approach. Int. J. Logist. Manag. 2019, 30, 303-328. [CrossRef]

42. Benitez, J.; Llorens, J.; Braojos, J. How information technology influences opportunity exploration and exploitation firm's capabilities. Inf. Manag. 2018, 55, 508-523. [CrossRef]

43. March, J.G. Exploration and exploitation in organizational learning. Organ. Sci. 1991, 2, 71-87. [CrossRef]

44. Hart, S.L. Beyond greening: Strategies for a sustainable world. Harv. Bus. Rev. 1997, 75, 66-77.

45. Min, S.; Zacharia, Z.G.; Smith, C.D. Defining Supply Chain Management: In the Past, Present, and Future. J. Bus. Logist. 2019, 40, 44-55. [CrossRef]

46. Cerchione, R.; Singh, R.; Centobelli, P.; Shabani, A. Food cold chain management: From a structured literature review to a conceptual framework and research agenda. Int. J. Logist. Manag. 2018, 29, 792-821. [CrossRef]

47. Daugherty, P.J.; Bolumole, Y.; Grawe, S.J. The new age of customer impatience: An agenda for reawakening logistics customer service research. Int. J. Phys. Distrib. Logist. Manag. 2019, 49, 4-32. [CrossRef]

48. Hoehle, H.; Aloysius, J.A.; Chan, F.; Venkatesh, V. Customers' tolerance for validation in omnichannel retail stores: Enabling logistics and supply chain analytics. Int. J. Logist. Manag. 2018, 29, 704-722. [CrossRef]

49. Lusch, R.F. Reframing supply chain management: A service-dominant logic perspective. J. Supply Chain Manag. $2011,47,14-18$. [CrossRef]

50. Stolze, H.J.; Mollenkopf, D.A.; Flint, D.J. What is the right supply chain for your shopper? Exploring the shopper service ecosystem. J. Bus. Logist. 2016, 37, 185-197. [CrossRef]

51. Tortorella, G.; Giglio, R.; Fettermmann, D.C.; Tlapa, D. Lean supply chain practices: An exploratory study on their relationship. Int. J. Logist. Manag. 2018, 29, 1049-1076. [CrossRef]

52. Tanco, M.; Escuder, M.; Heckmann, G.; Jurburg, D.; Velazquez, J. Supply chain management in Latin America: Current research and future directions. Supply Chain Manag. Int. J. 2018, 23, 412-430. [CrossRef]

53. Barney, J. Firm resources and sustained competitive advantage. J. Manag. 1991, 17, 99-120. [CrossRef]

54. Yang, J.; Han, Q.; Zhou, J.; Yuan, C. The influence of environmental management practices and supply chain integration on technological innovation performance-Evidence from China's manufacturing industry. Sustainability 2015, 7, 15342-15361. [CrossRef]

55. Rajaguru, R.; Matanda, M.J. Effects of inter-organizational compatibility on supply chain capabilities: Exploring the mediating role of inter-organizational information systems (IOIS) integration. Ind. Mark. Manag. 2013, 42, 620-632. [CrossRef]

56. Morgan, T.R.; Richey, R.G., Jr.; Autry, C.W. Developing a reverse logistics competency: The influence of collaboration and information technology. Int. J. Phys. Distrib. Logist. Manag. 2016, 46, 293-315. [CrossRef] 
57. Selviaridis, K.; Matopoulos, A.; Thomas Szamosi, L.; Psychogios, A. Reverse resource exchanges in service supply chains: The case of returnable transport packaging. Supply Chain Manag. Int. J. 2016, 21, 381-397. [CrossRef]

58. Maley, J.F.; Kowalkowski, C.; Brege, S.; Biggemann, S. Outsourcing maintenance in complex process industries: Managing firm capabilities in lock-in effect. Asia Pac. J. Mark. Logist. 2015, 27, 801-825. [CrossRef]

59. Teece, D.J.; Pisano, G.; Shuen, A. Dynamic capabilities and strategic management. Strateg. Manag. J. 1997, 18, 509-533. [CrossRef]

60. March, J.G. Rationality, foolishness, and adaptive intelligence. Strateg. Manag. J. 2006, 27, 201-214. [CrossRef]

61. Thai, V.; Jie, F. The impact of total quality management and supply chain integration on firm performance of container shipping companies in Singapore. Asia Pac. J. Mark. Logist. 2018, 3, 605-626. [CrossRef]

62. Fawcett, S.E.; Wallin, C.; Allred, C.; Fawcett, A.M.; Magnan, G.M. Information technology as an enabler of supply chain collaboration: A dynamic-capabilities perspective. J. Supply Chain Manag. 2011, 47, 38-59. [CrossRef]

63. Hill, C.A.; Zhang, G.P.; Miller, K.E. Collaborative planning, forecasting, and replenishment \& firm performance: An empirical evaluation. Int. J. Prod. Econ. 2018, 196, 12-23.

64. Ghadge, A.; Weiß, M.; Caldwell, N.D.; Wilding, R. Managing cyber risk in supply chains: A review and research agenda. Supply Chain Manag. Int. J. 2019, 25, 223-240. [CrossRef]

65. Wang, M.; Jie, F.; Abareshi, A. Evaluating logistics capability for mitigation of supply chain uncertainty and risk in the Australian courier firms. Asia Pac. J. Mark. Logist. 2015, 27, 486-498. [CrossRef]

66. Park, K.O. A Study on Sustainable Usage Intention of Blockchain in the Big Data Era: Logistics and Supply Chain Management Companies. Sustainability 2020, 12, 10670. [CrossRef]

67. Song, Y.; Cai, J.; Feng, T. The influence of green supply chain integration on firm performance: A contingency and configuration perspective. Sustainability 2017, 9, 763. [CrossRef]

68. Vachon, S.; Klassen, R.D. Supply chain management and environmental technologies: The role of integration. Int. J. Prod. Res. 2007, 45, 401-423. [CrossRef]

69. Pérez-Mesa, J.C.; Piedra-Muñoz, L.; Galdeano-Gómez, E.; Giagnocavo, C. Management Strategies and Collaborative Relationships for Sustainability in the Agrifood Supply Chain. Sustainability 2021, 13, 749. [CrossRef]

70. Sevensson, G.; Ferro, C.; Hogevold, N.; Padin, C.; Sosa Varela, J.C. Developing a theory of focal company business sustainability efforts in connection with supply chain stakeholders. Supply Chain Manag. Int. J. 2018, 23, 16-32. [CrossRef]

71. Chen, L.; Zhao, X.; Tang, O.; Price, L.; Zhang, S.; Zhu, W. Supply chain collaboration for sustainability: A literature review and future research agenda. Int. J. Prod. Econ. 2017, 194, 73-87. [CrossRef]

72. Plaza-Úbeda, J.A.; Abad-Segura, E.; Burgos-Jiménez, J.D.; Boteva-Asenova, A.; Belmonte-Ureña, L.J. Trends and New Challenges in the Green Supply Chain: The Reverse Logistics. Sustainability 2021, 13, 331. [CrossRef]

73. Wei, C.F.; Chiang, C.T.; Kou, T.C.; Lee, B.C. Toward sustainable livelihoods: Investigating the drivers of purchase behavior for green products. Bus. Strategy Environ. 2017, 26, 626-639. [CrossRef]

74. Habib, M.; Bao, Y.; Nabi, N.; Dulal, M.; Asha, A.A.; Islam, M. Impact of Strategic Orientations on the Implementation of Green Supply Chain Management Practices and Sustainable Firm Performance. Sustainability 2021, 13, 340. [CrossRef] 